\title{
UM CONVITE À NAVEGAÇÃO: INTERCULTURALIDADE E PROCESSOS DE LEITURA
}

\section{AN INVITATION TO NAVIGATION: INTERCULTURALITY AND READING PROCESSES}

Teresa Beatriz Azambuya Cibotari ${ }^{1}$

\begin{abstract}
Resumo: O presente trabalho propõe-se a discutir a obra Ombela (2015), do escritor angolano Ondjaki, que é uma produção voltada para o público infantil. A análise busca estabelecer diálogos entre contextos de produção e de recepção, observando como se dá o trânsito de elementos culturais entre grupos diferentes de leitores, falantes de uma mesma língua, no caso, a língua portuguesa. A análise ainda postula possibilidades de trabalho com essa obra literária no contexto educacional brasileiro.
\end{abstract}

\begin{abstract}
The present work proposes to discuss the book Ombela (2015) which is a production with a focus on children, written by the Angolan writer Ondjaki. The analysis establishes dialogues between production and reception contexts, observing how the transit of cultural elements takes place between different groups of readers, who speak the same language, in this case, the Portuguese language. The analysis also proposes possibilities for working with this literary work in the Brazilian educational context.
\end{abstract}

Palavras-chave: Literatura africana; Ombela; Leitura; Interculturalidade.

Keywords: African literature; Ombela; Reading; Interculturality.

\section{Os muitos nós que somos}

O empreendimento civilizatório do império português, para além da violência e da opressão com que operou, criou um espaço linguístico comum, habitado por pessoas de vários continentes. América, África, Ásia e Europa têm milhares de falantes em língua portuguesa, compartilhando códigos de comunicação que funcionam como um dos elementos enunciadores da identidade de uma grande comunidade.

No entanto, o compartilhamento desse idioma comum pode ter limites, quando pensamos nas diversas culturas que dele fazem uso e quando consideramos a incorporação de elementos da cultura local à língua utilizada, que é sempre viva. A discussão ultrapassa a questão lexical, atinge a sintaxe e todos os demais componentes comunicativos que fundam um sistema linguístico. É por isso que a língua portuguesa falada em Angola, por exemplo, é a mesma falada no Brasil, mas os diversos fatores que incidem sobre esse idioma em cada um desses espaços podem ocasionar variações

\footnotetext{
1 Doutoranda e mestre em Teoria da Literatura pela Pontifícia Universidade Católica do Rio Grande do Sul (PUCRS).
} 
das mais diferentes ordens, o que pode dificultar, em alguma medida, a inteligibilidade de textos produzidos naquele país por leitores brasileiros, por exemplo. Se os leitores são seres históricos, assim como defende Escarpit (1974), na obra Hacia una sociología del hecho literário, é preciso também acrescentar o atributo geográfico a essa caracterização.

Nesse contexto, interessa-nos observar os processos de leitura num contexto ainda mais específico, que é o da produção literária. A Literatura, por si só, já é um modo de comunicação bastante particular, que se dá através de um suporte: o livro. Assim sendo, na leitura de textos literários, mesmo que o idioma seja um código compartilhado por autor e leitor, é preciso pensar em ambos como seres históricos, geográficos e, também, essencialmente culturais, o que pode ensejar um conjunto amplo de variações na experiência de leitura de um texto.

Para além dessas questões, há uma problemática específica que norteia a presente discussão. No Brasil, a Lei Federal 10.639/2003 estabelece a obrigatoriedade, em todo o sistema educacional, do ensino de história e de cultura afro-brasileira. Se levarmos em conta que a maior parte da população brasileira é composta por pretos e pardos, segundo dados do $\mathrm{IBGE}^{2}$, a referida lei possibilita deslocar uma lógica eurocentrista no sistema curricular, oportunizando que a população em idade escolar tenha contato com a cultura afro, tão significativa no país. Acreditamos que a atuação dos docentes de Língua Portuguesa seja um caminho possível para fazer com que essa norma não seja letra morta dentro dos espaços educativos.

A leitura de obras literárias produzidas em países africanos de língua portuguesa pode constituir-se como uma possibilidade de trabalho para efetivar o cumprimento dessa lei, mas, mais do que isso, como uma forma de ampliar as referências culturais dos alunos e oportunizar a identificação dessa maioria populacional com elementos culturais próprios de suas origens. No entanto, se a língua comum pode ser a corda que liga todos esses falantes, as variações de registro, a expectativa do autor em relação a seu público leitor e as questões de conteúdo presentes nas obras podem dificultar essa leitura. Em que medida esses diferentes nós que somos estão atados a essa linha é o que pretendemos analisar.

A obra Ombela - a origem das chuvas (2015), do escritor angolano Ondjaki, é um livro ilustrado, voltado ao público infantil. Pensando na composição do livro, o que abrange as ilustrações, a forma textual e o conteúdo, pretendemos refletir acerca dos processos e das possibilidades de leitura, observando a comunicabilidade da obra e os possíveis ruídos que podem ocorrer na leitura feita pelo público escolar brasileiro.

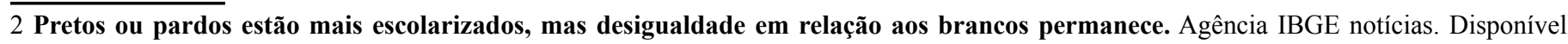
em: https://agenciadenoticias.ibge.gov.br/agencia-sala-de-imprensa/2013-agencia-de-noticias/releases/25989-pretos-ou-pardos-estao-maisescolarizados-mas-desigualdade-em-relacao-aos-brancos-permanece. Acesso em: 14 de novembro de 2019.
} 


\title{
Por mares e lagos: o choro de Ombela e a produção de sentidos
}

Ombela é uma deusa que chora. Suas lágrimas de tristeza caem sobre o mar salgado; suas lágrimas de felicidade desaguam em rios e lagos. Por elas é que a protagonista do conto convida seus leitores a navegar. A obra foi escrita pelo autor angolano Ondjaki, ilustrada por Rachel Caiano, artista plástica brasileira, e publicada, originalmente, em Portugal. Essa primeira perspectiva pré-textual é bastante enunciadora: situa a obra num contexto de trânsito cultural que tem como elemento comum a língua portuguesa.

Na abertura do livro, deparamo-nos com uma ilustração bastante característica: chove sobre um embondeiro, árvore típica de Angola. Na página seguinte, onde estão os elementos catalográficos da obra, chove sobre dois pés negros. E a terceira abertura de página apresenta uma menina negra que chora. Ao lado dessa imagem, inicia o texto:

\author{
Dizem os mais-velhos \\ que a chuva nasceu \\ das lágrimas de Ombela, \\ uma deusa que estava muito triste.
}

(ONDJAKI, 2015, p. 7).

A ambientação inicial traz diversos elementos que compõem um cenário cultural tipicamente angolano ou, pode-se dizer, africano. Desde a apresentação de uma paisagem específica, passando pela personagem negra, até o ingresso do texto em si, há vários elementos que enunciam essa cultura. A utilização da expressão "mais-velhos", grafada com hífen, remete a um uso bastante particular da língua portuguesa falada em Angola: trata-se não apenas de pessoas de mais idade, mas refere um grupo que detém os saberes ancestrais da sociedade. Além disso, está presente, nesse trecho, a questão da oralidade, tão importante nas culturas africanas: o relato provém de histórias contadas por esse grupo. Por fim, é necessário destacar que o leitor é também colocado diante de uma expressão religiosa característica daquela cultura, visto que a protagonista é uma deusa, ou seja, além de mulher, ela é apenas uma, o que pressupõe a existência de vários outros deuses.

Existe, portanto, um mundo que está sendo apresentado ao leitor. Segundo Ricoeur (1997), trata-se do mundo do texto, ou seja, há um conjunto de informações posto, de forma imanente, que está à espera de um leitor capaz de desvendá-lo. O universo ficcional que aparece logo na abertura do livro é integrado por elementos culturais próprios, o que pode ter um sentido específico. Pensando no conceito de autor implicado abordado por Ricoeur, podemos dizer que tal ambientação faz parte de uma estratégia de persuasão efetuada por esse autor implicado, que deseja apresentar ao leitor 
um contexto cultural bastante particular. Para isso, contribui não somente o texto, como também as ilustrações, que integram essa estratégia textual.

Ricoeur (1997) trata também do apagamento do autor como uma estratégia de persuasão, e é nesse sentido que apresenta a noção de autor implicado. O autor menciona a existência de uma "retórica da dissimulação", por meio da qual a história parece contar-se sozinha. Assim define:

Os procedimentos retóricos pelos quais o autor sacrifica sua presença consistem precisamente em dissimular o artifício pela verossimilhança de uma história que parece contar-se sozinha e deixar falar a vida, que, assim, é chamada de realidade social. (RICOEUR, 1997, p. 279).

Isso é o que ocorre quando a história de Ombela é atribuída a um relato dos "mais-velhos". Além de marcar a presença da oralidade, o recurso narrativo expõe uma estratégia de persuasão que compõe a presença de um autor implicado, surgido a partir do apagamento do autor real. Isso é importante para pensarmos nessa obra, justamente porque ela é uma obra em trânsito, ou seja, há um autor angolano e uma ilustradora brasileira, mas eles se apagam na realização do texto, uma vez que toda a construção - tanto textual quanto imagética - trabalham no mesmo sentido e a serviço de uma mesma estratégia, que é a de inserir o leitor no universo cultural africano.

A sequência da obra muda um pouco seu traçado e convida-nos a um caminho mais largo, mais universal. Surge o mar, aparecem os peixes, e Ombela parece preocupada em não afetar todo o planeta com sua tristeza:

$$
\begin{aligned}
& \text { Estou triste e vou chorar... } \\
& \text { mas para que minhas lágrimas não } \\
& \text { matem os bichos nem as pessoas que vivem } \\
& \text { na Terra, vou deixar que tenham muito sal } \\
& \text { e que alimentem todos os mares. }
\end{aligned}
$$

(ONDJAKI, 2015, p. 9).

A perspectiva enunciada a partir desse momento é a de uma cultura local capaz de afetar o mundo todo. Ombela, a deusa, sente-se responsável por manter o equilíbrio da natureza. Mesmo em sua imensa tristeza, toma cuidado para prover alimento aos peixes, e é assim que suas lágrimas salgadas alimentam os mares. Da mesma maneira ocorre com o texto: a partir desse momento, não se verificam mais marcas específicas de uso local da língua portuguesa; o texto flui, sem maiores dificuldades, na mesma corrente dos mares, rios e lagos sobre os quais Ombela chora. 
A representação da cultura local, ao longo do restante do texto, fica por conta das ilustrações e do conteúdo. Sobre este último aspecto, cabe uma anotação: Ombela está em constante diálogo com seu pai, que também é um deus e que se permite diminuir:

- E tu, pai, quando estás triste, o que te acontece?

- Fico mais pequenino, filha.

- Os deuses podem ficar mais pequenos?

- Podem - respondeu o pai de Ombela. - Os deuses, com o passar do tempo, ficam cada vez mais pequenos.

(ONDJAKI, 2015, p. 13).

Tal contexto é bastante específico se pensarmos nos termos de um pensamento anímico no qual se funda a cultura africana. Saraiva (2007), no texto "O realismo animista e o espaço não-nostálgico em narrativas africanas de língua portuguesa", diferencia os gêneros do realismo maravilhoso, do realismo mágico e do realismo fantástico, que são insuficientes para categorizar as narrativas africanas. Nesse sentido, refere-se ao termo "realismo anímico", proposto por Pepetela e Henrique Abranches, baseando-se na ideia de que

nas literaturas africanas a natureza dos acontecimentos está calcada nas crenças religiosas animistas, 'nos antepassados e em poderes que existem na natureza', isto é, no estatuto do sobrenatural. (SARAIVA, 2007, p. 4).

Assim sendo, a estreita relação com a natureza na qual se baseia o pensamento anímico é recorrente nas narrativas africanas. Nesse contexto, um deus que pode se tornar diminuto é perfeitamente possível na cosmovisão religiosa africana, ao passo que se configura como uma possibilidade inexistente na cultura judaico-cristã.

As imagens que ilustram o restante da obra encarregam-se de complementar a apresentação do cenário cultural africano. Cores e traçados étnicos; imagens da deusa Ombela, que é negra; elefantes, hienas, compõem a paisagem úmida, auxiliam na formulação do mito que explica a origem das chuvas: "Se essa chuva cai sobre o mar, Ombela está triste" (ONDJAKI, 2015, p. 32); "Se cai sobre a terra, sobre os rios, sobre os lagos, Ombela está feliz.” (ONDJAKI, 2015, p. 33).

Se o texto, ressalvado o início da obra, parece estar neutralizado, o conteúdo e as imagens são altamente carregados de elementos culturais bastante particulares. Isso também integra uma 
estratégia de persuasão, destinada a encontrar o mundo do leitor, segundo o conceito de Ricoeur (1997). Somente na intersecção entre esses dois mundos - o do texto e o do leitor - é que se dará a significância da obra, o que será discutido a seguir.

\section{Um barco a navegar: processos de leitura}

Como vimos até o momento, Ombela (2015) é uma narrativa africana intensamente povoada de elementos culturais próprios. No entanto, pensando nos usos particulares da língua portuguesa feita em África, que costuma integrar vocabulário e termos das línguas locais, é importante frisar que, textualmente, não há marcas linguísticas muito particulares, à exceção do uso da expressão "maisvelhos", assim hifenizada, no início e no final da obra.

A inserção do leitor em um universo tão rico culturalmente se dá, portanto, especialmente pelo conteúdo e pelas ilustrações. Considerando que essa apresentação seja estratégica, podemos pensar que o encontro do mundo do texto e do mundo do leitor promova a operação de significância em dois sentidos distintos: primeiro, se o leitor compartilhar do mesmo conhecimento ou realidade que apresenta o mundo do texto, ou seja, um leitor angolano; e segundo, se o leitor não compartilhar de todos os elementos dessa realidade, como seria o caso de um leitor / aluno brasileiro.

Antes, porém, de comentarmos o sentido específico desses dois caminhos, é preciso considerar que, quando se trata de atribuir a um caráter de nacionalidade a detenção de certos conhecimentos compartilhados, fazemos de uma forma genérica e hipotética. É possível haver situações de leitura específicas em que tanto brasileiros quanto angolanos compartilhem do mesmo mundo de sentidos que propõe o texto. Mas, para melhor desenvolver a análise, estabeleceu-se a separação pelo aspecto nacional, a fim de pensar em conjuntos de saberes culturais diferenciados, que podem ser integrados por meio da língua ou da experiência de leitura.

Umberto Eco (2011, p. 37), ao discutir a questão do leitor-modelo, atribui ao destinatário do texto a qualidade de operador de determinados postulados de significado: "todo o texto quer que alguém o ajude a funcionar", afirma o autor. No entanto, considerando que a competência do destinatário pode não ser a mesma do emitente, o autor de uma obra, ao escrevê-la, prevê um "leitormodelo", que seja capaz de cooperar para a constituição de sentidos. Essa construção estratégica é feita por um autor-modelo, que corresponde, em certa medida, ao conceito de autor implicado proposto por Ricoeur (1997). 
No caso da obra Ombela (2015), de Ondjaki, é inegável que existe uma estratégia de proporcionar o contato do público leitor infantil com aspectos próprios da cultura africana, por meio da narrativa de um mito de origem. Isso se dá, no início da obra, em três níveis: textual, conteudístico e imagético. Na sequência do texto, a apresentação de elementos particulares fica somente nos dois últimos níveis, restando a questão textual como elemento aparentemente neutralizado, se pensarmos na incorporação de vocabulário específico da língua local. Assim, o texto pode ser lido sem maiores problemas por qualquer falante da língua portuguesa, seja ele brasileiro, angolano ou português.

A partir disso, pode-se depreender que as estratégias de persuasão do autor implicado nessa obra direcionam-se a um leitor-modelo não autóctone, ou seja, um leitor que não compartilha do mesmo léxico africano. Ao permitir, num uso mais "universalizante" da língua portuguesa, que haja uma leitura fluente da história de Ombela, a obra torna-se acessível a uma quantidade maior de leitores, dos países luso-falantes. Isso oportuniza que esses leitores conheçam elementos da cultura africana, sem que a língua seja um obstáculo à compreensão, o que muitas vezes acontece em narrativas de Angola, Moçambique, ou outros países africanos de expressão portuguesa, mesmo se destinadas a um público infantil.

Obviamente, há uma dupla questão a ser apontada nesse caso. Se, por um lado, a neutralização operada no nível textual facilita o acesso de mais leitores, por outro lado, reduz as possibilidades de conhecimento acerca dos diversos usos que podem ser feitos em uma mesma língua, o que também é um aprendizado importante. Claro que, como vimos, essa é uma estratégia de persuasão constituída no texto. A obra Ombela (2015) pode, nesse sentido, servir como uma forma de acesso dos leitores brasileiros a esse universo cultural, e cabe ao docente de Língua Portuguesa ir oferecendo materiais de leitura que ampliem essas possibilidades.

É preciso notar, porém, que, mesmo que os elementos culturais particulares sejam apresentados de forma mais significativa pelas imagens, facilitando a leitura e o acesso, este não é um recurso menos importante. Colomer (2007) salienta, em relação à ilustração de obras infantis, que

os melhores livros ilustrados são aqueles que estabelecem um compromisso entre o que as crianças podem reconhecer facilmente e o que podem compreender através de um esforço imaginário. (COLOMER, 2007, p. 57).

A obra do escritor angolano Ondjaki foi criada justamente nesse sentido. As imagens presentes na obra, sugeridas a partir de traços étnicos ou de silhuetas da fauna local, por exemplo, permite que a criança reconheça uma hiena, uma galinha, mas lhe exige o esforço imaginário, a abertura para esse 
discurso, ainda que imagético, proveniente da cultura africana.

Num outro sentido, ainda que a obra seja lida num contexto africano, particularmente angolano, ainda que o leitor facilmente reconheça traços, conteúdos e expressões da cultura local, ela não deixa de ser interessante, visto que o leitor autóctone pode apreciá-la pela via da identificação, ou seja, pela experiência de também se encontrar representado nas imagens ou, até mesmo, na expressão anímica que a obra ilustra.

Em tais circunstâncias, a obra Ombela - a origem das chuvas (2015) pode ser perfeitamente usada com alunos / leitores do cenário educativo brasileiro. Trata-se de uma experiência enriquecedora de leitura, justamente pelo trânsito que suas estratégias estéticas configuram: de um lado, considerando a hipótese de um leitor não autóctone, ela permite o contato com essa cultura tão rica e diversa quanto a africana. Por outro lado, considerando, como dissemos no início, que a maior parte da população brasileira é negra, a identificação tanto com os personagens negros ali representados quanto com a expressão anímica que ali está posta (é preciso pensar que muitos alunos provêm de famílias que frequentam a religião de matriz africana) faz com que ela se revele como uma importante leitura a ser proporcionada a esses alunos.

Colomer (2007) destaca justamente a necessidade dessas leituras diversificadas para ampliar as competências dos alunos no processo educativo e no letramento literário. Dessa forma, assevera que

o objetivo da educação literária é, em primeiro lugar, o de contribuir para a formação da pessoa, uma formação que aparece ligada indissoluvelmente à construção da sociabilidade e realizada através da confrontação com textos que explicitam a forma em que as gerações anteriores e as contemporâneas abordaram a avaliação da atividade humana através da linguagem.

Em segundo lugar o confronto entre textos literários distintos oferece ao aluno a ocasião de enfrentar a diversidade social e cultural, no momento em que têm início as grandes questões filosóficas propostas ao longo do tempo. (COLOMER, 2007, p. 31, grifos da autora).

No caso, a leitura de Ombela (2015), além de ser uma possibilidade de atender a exigência da lei federal que determina o ensino de cultura africana nas escolas, oferece-se como oportunidade de ampliar o repertório cultural dos alunos, contribuindo para sua formação pessoal e proporcionando recursos para observar a diversidade social e cultural que funda nosso país.

Obviamente, há sempre algo que pode escapar a uma apreciação positiva. Toda a perspectiva 
até aqui enaltecida, que contempla a apresentação de elementos culturais diversos, a exigência de um esforço imaginário por parte do leitor ou a elaboração narrativa acessível pode esbarrar na questão do conteúdo religioso. Escolas confessionais, por exemplo, poderiam censurar a leitura da obra por parte dos alunos, considerando os aspectos anímicos próprios da cultura, conforme abordamos anteriormente. Uma deusa feminina e um deus diminuto podem confrontar cosmovisões estabelecidas, especialmente cristãs, o que poderia ensejar censura à leitura da obra. No entanto, mesmo nesse contexto, é possível organizar métodos de trabalho que coloquem a obra como fonte de conhecimento e de respeito à pluralidade cultural, preservando, de todo o modo, o direito de crença ${ }^{3}$.

\section{Considerações finais}

O livro Ombela (2015) é um convite a várias formas de navegação, pelos mares, pelos rios, pelas lágrimas de sua protagonista. As estratégias textuais engendradas permitem afirmar que é uma obra pensada para um leitor-modelo não autóctone, a quem se deseja convidar para que conheça a cultura africana. Ao leitor que aceitar o convite, caberá navegar por esse universo tão rico, tão bonito imageticamente, e conhecer um dos mitos existentes acerca da origem das chuvas.

É preciso considerar que a formação cultural brasileira é essencialmente fundada na diversidade, e as raízes africanas são parte relevante nessa formação. No entanto, a oferta de materiais que possibilitem, de um lado, o conhecimento acerca dessa cultura e, de outro, a identificação de muitos descendentes de africanos com elementos culturais próprios, nem sempre acontece. Nessas circunstâncias é que se deu a implementação da legislação que exige o ensino de história e de cultura africana no sistema escolar brasileiro.

Assim sendo, avaliamos que a obra Ombela, por se constituir como uma narrativa de elementos culturais próprios da África e por fazê-lo de uma forma bastante acessível em termos de linguagem, pode ser um importante instrumento de leitura literária com alunos do contexto educativo brasileiro, especialmente como uma possibilidade de ambientação e de inserção dos alunos no contato com esse repertório de leituras.

\footnotetext{
3 A obra Ombela compôs o catálogo de livros trabalhados no projeto "Vamos conhecer a África?", desenvolvido por esta pesquisadora em escolas de ensino fundamental, da cidade de Gravataí-RS (uma pública e outra privada). No caso específico da escola privada, de confissão religiosa, não se admitiu a possibilidade de que os alunos tivessem contato com uma narrativa que previsse a existência de muitos deuses. Mesmo propondo métodos de trabalho que privilegiassem o diálogo, a escola optou por retirar essa obra do projeto.
} 


\section{Referências}

COLOMER, Teresa. Andar entre livros: a leitura literária na escola. Tradução de Laura Sandroni. São Paulo: Global, 2007.

ECO, Umberto. Lector in fabula: a cooperação interpretativa nos textos narrativos. Tradução de Attílio Cancian. São Paulo: Perspectiva, 2011.

ESCARPIT, Robert. Hacia una sociología del hecho literario. Madrid: Edicusa, 1974.

IBGE. Pretos ou pardos estão mais escolarizados, mas desigualdade em relação aos brancos permanece. Agência IBGE notícias. Disponível em: https://agenciadenoticias.ibge.gov.br/agencia-sala-de-imprensa/2013-agencia-de-noticias/ releases/25989-pretos-ou-pardos-estao-mais-escolarizados-mas-desigualdade-em-relacao-aos-brancos-permanece. Acesso em: 14 de novembro de 2019.

ONDJAKI. Ombela - A origem das chuvas. Alfragide: Editorial Caminho, 2015.

RICOEUR, Paul. Tempo e narrativa - Tomo III. Tradução de Roberto Leal Ferreira. Campinas (SP): Papirus, 1997, p. 273-314.

SARAIVA, Sueli da Silva. O realismo animista e o espaço não-nostálgico em narrativas africanas de língua portuguesa. Encontro Regional da ABRALIC 2007. Literaturas, Artes, Saberes. São Paulo, 2007. 